\title{
When Will My Esophagus Be Fixed?
}

\author{
Zhao Liang Li and Hiroto Miwa* \\ Division of Upper Gastroenterology, Department of Internal Medicine, Hyogo College of Medicine, Nishinomiya, Hyogo, Japan
}

Article: Clinical analysis of primary eosinophilic esophagitis

Lee JH, Kim MJ, Kim JH, et al

(J Neurogastroenterol Motil 2013;19:204-209)

Eosinophilic esophagitis $(\mathrm{EoE})$ is a rare disease, but the prevalence has recently been increasing significantly, particularly in Western countries. Recent reports have shown that this condition is also increasing in Asia and the Middle East. The mechanisms underlying the development of EoE have been intensively investigated, although details of the pathophysiology remain unclear. From the clinical perspective, diagnostic and management algorithms have been proposed and consensus recommendations were updated in 2011, improving the consensus on this pathology. However, arguments remain regarding the details of diagnosis and treatment.

EoE is defined in the updated consensus recommendations ${ }^{1}$ as 'a chronic, immune/antigen-mediated, esophageal disease characterized by symptoms related to esophageal dysfunction and histologically by eosinophil-predominant inflammation,' and is regarded as an allergic disease. In fact, evidence of atopic disease is identifiable in $60-80 \%$ of EoE patients, manifesting as asthma, eczema, food sensitivities, elevated serum immunoglobulin E levels or peripheral eosinophilia. ${ }^{2}$ Furthermore, reports of adult EoE have also shown a marked increase recently, although EoE has been thought to occur most often in the infant period.
The mechanism of onset for EoE is considered to involve allergens such as certain foods arriving at the esophageal mucous membrane and there stimulating $\mathrm{TH} 2$ immune responses through the overexpression of thymic stromal lymphopoietin, leading to chronic inflammation with eosinophilic infiltration mediated via IL-5, IL-13 and eotaxin-3. ${ }^{1,3}$ In addition, persistence of inflammation is considered to induce fibrosis or changes in the esophageal structure, as so-called 'tissue remodeling.' The mechanisms of this phenomenon have yet to be fully investigated, but TGF- $\beta 1$ derived from eosinophils or mast cells is suspected to play a crucial role, ${ }^{4}$ similar to the pathogenic mechanisms of bronchial asthma.

With advances in the understanding of its pathogenesis, treatment of EoE is also progressing. First-line treatments include dietary restriction and steroid therapy, and therapy with proton pump inhibitors (PPIs) has been introduced as an initial treatment option. PPI treatment has recently been revisited with reports of PPI-responsive esophageal eosinophilia, anti-inflammatory actions of PPIs and inhibitory effects on the production of eotaxin-3 in the squamous epithelium of the esophagus. ${ }^{6}$ Regarding steroid therapy and dietary restrictions, many reports have

Received: April 5, 2013 Revised: None Accepted: April 5, 2013

(c) This is an Open Access article distributed under the terms of the Creative Commons Attribution Non-Commercial License (http://creativecommons. org/licenses/by-nc/3.0) which permits unrestricted non-commercial use, distribution, and reproduction in any medium, provided the original work is properly cited.

*Correspondence: Hiroto Miwa, MD, PhD

Division of Upper Gastroenterology, Department of Internal Medicine, Hyogo College of Medicine, Mukogawacho, Nishinomiya city, Hyogo 663-8501, Japan

Financial support: None.

Tel: +81-798-45-6665, Fax: +81-798-45-6665, E-mail: miwahgi@hyo-med.ac.jp

Conflicts of interest: None. 
shown constant effects. The dietary therapy provided for infants has been applied to adults, resulting in favorable outcomes.

A recent report from Chicago ${ }^{7}$ showed that clinical manifestations decreased in $94 \%$ of EoE patients after the 6-food elimination diet (milk, soy, egg, wheat, peanuts/tree nuts and shellfish/fish), and reintroduction of these foods re-initiated the features of EoE. The report finally revealed that $\mathrm{EoE}$ is induced by wheat $(50 \%)$ and milk (60\%).

One of the remaining problems is recurrence after treatment. In fact, many reports have shown that relapse rates after steroid therapy are high. However, there is no widely accepted definition of recurrence for this condition, and only a few reports have precisely described the details of the recurrence. Does EoE recur after being healed once, or does EoE remain even if a cure seems to have been achieved? No studies have yet answered this question. In this issue of this journal, Lee et $\mathrm{al}^{8}$ studied this clinical question from the perspective of the dissociation between endoscopic findings and clinical symptoms. They found that endoscopic findings generally remained unimproved after treatment, even though symptoms and eosinophil counts of EoE improved. They speculated that endoscopic findings may suggest irreversible structural changes, representing 'remodeling' similar to that seen in bronchial asthma. In other words, deformity of the esophageal structures due to eosinophilic inflammation may remain long after symptomatic improvement. This may be why EoE recurs so often. Although basically an observational study, their findings provide interesting insights into the pathogenesis and mechanisms of recurrence for this disease, representing a step toward understanding EoE. Further prospective observational studies into the natural history of this condition should be carried out to truly answer this question.

\section{References}

1. Liacouras CA, Furuta GT, Hirano I, et al. Eosinophilic esophagitis: updated consensus recommendations for children and adults. J Allergy Clin Immunol 2011;128:3-20.

2. Fox VL, Nurko S, Teitelbaum JE, Badizadegan K, Furuta GT. High-resolution EUS in children with eosinophilc 'allergic' esophagitis. Gastrointest Endoscopy 2003;57:30-36.

3. Furuta GT, Liacouras CA, Collins MH, et al. Endoscopic esophagitis in children and adults: a systemic review and consensus recommendations for diaiagnosis and treatment. Gastroenterology 2007; 133:1342-1363.

4. Lucendo AJ, Arias A, De Rezende LC, et al. Subepithelial collagen deposition, profibrogenic cytokine gene expression, and changes after prolonged fluticasone propionate treatment in adult eosinophilic esophagitis: a prospective study. J Allergy Clin Immunol 2011;128: 1037-1046.

5. Aceves SS, Broide DH. Airway fibrosis and angiogenesis due to eosinophil trafficking in chronic asthma. Curr Mol Med 2008;8:350358.

6. Cheng E, Zhang X, Huo X, et al. Omeprazole blocks eotaxin-3 expression by oesophageal squamous cells from patients with eosinophilic oesophagitis and GORD. Gut Published Online First: 12 May 2012. doi:10.1136/gutjnl-2012-302250

7. Gonsalves N, Yang GY, Doerfler B, Rotz S, Ditto AM, Hirano I. Elimination diet effecitively treats eosinophilic esophagitis in adults; food reintroduction identifies causative factors. Gastroenterology 2012;142:1451-1459.e1.

8. Lee JH, Kim MJ, Kim JH, et al. Clinical analysis of primary eosinophilic esophagitis. J Neurogastroenterol Motil 2013;19:204-209. 